Article

\title{
Rickettsia africae an Agent of African Tick Bite Fever in Ticks Collected from Domestic Animals in Eastern Cape, South Africa
}

\author{
Benson Chuks Iweriebor ${ }^{1, *(\mathbb{D}}$, Ayabulela Nqoro ${ }^{2,3}$ and Chikwelu Larry Obi $^{1}$ \\ 1 School of Science and Technology, Sefako Makgatho Health Sciences University, Ga-Rankuwa, \\ Pretoria 0208, South Africa; lawrence.obi@smu.ac.za \\ 2 SAMRC Microbial Water Quality Monitoring Centre, Department of Biochemistry and Microbiology, \\ University of Fort Hare, Alice 5700, South Africa; 201407896@ufh.ac.za \\ 3 Applied and Environmental Microbiology Research Group (AEMREG), Department of Biochemistry and \\ Microbiology, University of Fort Hare, Alice 5700, South Africa \\ * Correspondence: benson.iweriebor@smu.ac.za; Tel.: +27-7609-9726
}

Received: 16 June 2020; Accepted: 17 July 2020; Published: 2 August 2020

\begin{abstract}
Background: Ticks transmit a plethora of pathogens of zoonotic implications. Their distribution, diversity and the pathogens they transmit differ from one ecological location to another. Rickettsia africae is the agent of African tick bite fever found in South Africa, a zoonotic infection that is frequently reported among travelers who have visited many sub-Saharan African countries where the pathogen is prevalent. Methods: Ticks were collected from domestic animals in Raymond Nkandla Municipality, Eastern Cape, South Africa. The ticks were identified morphologically prior to DNA extraction followed by molecular identification of randomly selected ticks from the morphologically delineated groups. To assess for the presence of tick-borne pathogens belonging to Rickettsia spp. by PCR (polymerase chain reaction), we used specific primer pairs targeting the $g l t \mathrm{~A}, \operatorname{omp} \mathrm{A}$ and $о m p \mathrm{~B}$ genes. The selected amplified ticks, all positive $о m p \mathrm{~B}$ and forty three omp A amplicons were sequenced in a commercial sequencing facility. The obtained nucleotide sequences were edited and subjected to BLASTn for homology search and phylogenetic analyses were performed with MEGA 7 Version for genetic relationships with curated reference sequences in GenBank. Results: A total of 953 ticks collected in the study were delineated into three genera consisting of Amblyomma, Rhipicephalus and Hyalomma in decreasing order of abundance. The presence of rickettsial DNA was detected in 60/953 (6.3\%) from the three genera of ticks screened. Genetic analyses of the DNA sequences obtained showed that they have phylogenetic relationship to members of the spotted fever group rickettsiae with $R$. africae, being the predominant SFGR (spotted fever group rickettsiae) detected in the screened ticks. Conclusion: This report shows that $R$. africae is the predominant spotted fever group rickettsiae in ticks collected from domestic animals in the study area and the human health impacts are not known.
\end{abstract}

Keywords: ticks; South Africa; spotted fever group rickettsiae; R. africae; African tick bite fever

\section{Introduction}

Tick-borne pathogens have been identified as the etiologic agents of emerging important human diseases especially in many tropical countries in Africa, Asia and South America [1]. In many sub-Saharan Africa countries, these diseases are rampant in rural communities where there are frequent contacts between humans and domestic animals that are hosts to these ticks [1,2]. Some rickettsioses are zoonotic diseases that are caused by some pathogenic Rickettsia spp. They are one of the oldest known vector-borne zoonotic diseases whose severity varies from one etiologic agent to another. There are 
many recognized species of Rickettsia that are delineated into four major groups namely; the typhus group consisting of two species which are $R$. typhi and $R$. prowazekii, the spotted fever group which contains many species that are exclusively transmitted to humans through ticks bites, the transitional group comprising of R. australis, R. akari and R. felis that are associated with ticks, mites and fleas and the ancestral group made up of $R$. bellii and R. canadensis. Beside these groups, there are also many other Rickettsia species that do exist but have not been fully characterized [2-4]. The current guidelines for the classification, delineation and description of novel rickettsial isolates are based on the $16 \mathrm{~S}$ rRNA gene, the differences in nucleotide sequence of $g l t \mathrm{~A}, \operatorname{omp} \mathrm{A}, \operatorname{omp} \mathrm{B}$, and the $\mathrm{D}$ genes that encodes for essential proteins in the organisms [5]. The global distribution of tick-borne rickettsioses varies from one region to another as their geographical spread are determined by their tick vectors whose distributions are generally governed by suitable environmental conditions like relative temperatures, humidity and biotopes which varies from one region to the other $[6,7]$.

Members of the genera Amblyomma, Hyalomma, Rhipicephalus, Ixodes, Dermacentor and Haemaphysalis are the species of ticks that are generally involved in the transmission of tick-borne rickettsioses in the tropical regions of the world [8,9]. Transmission of tick-borne rickettsioses could be either transstadial or transovarial thus making some tick species such as Amblyomma to be a known reservoir of R. africae [7]. In the Eastern Cape of South Africa, most common species of ticks are members of the genera; Amblyomma, Rhipicephalus, Haemaphysalis, and Hyalomma [8,9] which are well-known vectors of several zoonotic pathogens. While most tick-borne pathogens are linked to known tick vectors, it is possible in some cases for an etiologic agent of a particular disease to be indeterminate.

Prior to the development of molecular approaches which are highly selective and sensitive in disease diagnoses, several Rickettsia spp. had been detected in ticks but their roles in the etiology of diseases in humans were unrecognized. However, in recent times such species that were previously thought innocuous have now been directly linked to the etiology of human diseases [3,10]. R. africa is reportedly the most common cause of fever in travelers to Africa, after malaria. The incubation period ranges from 5-10 days and clinical manifestations include the main spot of inoculation, eschar, fever, myalgia, headache, rash, lymphadenitis and in some cases, reactive arthritis [11].

The Eastern Cape of South Africa is predominantly rural with intensive animal husbandry where the animals are kept in close proximity to homes. Couple with this is that there are many game reserves where these animals are in close contact with those in the wild. There exist great possibilities of these domesticated animals being infested with ticks from those originating from the wild thus making the spread of zoonotic pathogens possible in these localities. In addition, with the very high prevalence of HIV/AIDS in these rural communities, the chances of these immunocompromised patients coming down with zoonotic infections are equally very probable as they lack the competent immune system that ordinarily fights off these infections in healthy folks. Besides, most of the spotted fever group rickettsiae (SFGR) infections present with symptoms that are very much similar to flu and could thus be misdiagnosed by clinicians who might not consider them as top priority in diagnoses and treatments due to lack of laboratory diagnosis prior to commencement of treatments. This study therefore, was aimed at epidemiological surveillance for tick-borne Rickettsia pathogens in ticks collected from domestic animals in communities which are close to natural game reserves and human habitations in order to assess the likelihood of zoonotic diseases in humans who might be infested with ticks.

\section{Materials and Methods}

\subsection{Ethical Clearance}

The University of Fort Hare Ethics Committee granted the ethical clearance (REC-270710-02-RA) before the commencement of the study. Permission was granted by the farmers before any ticks collection could commence from their animals. Ticks collection was done with help of veterinary personnel and animal health technicians responsible for handling and treating the animals. Ethical 
clearance certificate (cert number: OBI013) was obtained from University of Fort Hare research and ethics committee (UREC).

\subsection{Study Area, Tick Collection and Identifications.}

The study was conducted from March 2017 to September 2018 in Raymond Mhlaba local Municipality in the Eastern Cape Province. Ticks collection sites and their geographical coordinates are as follows; Debe, with coordinates: $32.836^{\circ} \mathrm{S}, 27.154^{\circ} \mathrm{E}$, and Fort Beaufort with coordinates: $32^{\circ} 47^{\prime} 0^{\prime \prime} \mathrm{S}$, $26^{\circ} 38^{\prime} 0^{\prime \prime}$ E. Debe Location shares boundary with Great Fish Natural Reserve which boasts of some wild animals like antelope, boars, giraffe, deer, and others (study site map can be accessed through: https: //tse2.mm.bing.net/th?id=OIP.GvQ4IE1x4Slo9oTuUb9EBgHaEk\&pid=Api\&P=0\&w=284\&h=176).

\subsection{Ticks Collection and Studied Animals from Where Ticks Have Been Collected}

Ticks were collected manually from 350 domestic animals (goats, sheep, cattle and horses) by using forceps into $50 \mathrm{~mL}$ Nalgene tubes that contained $70 \%$ ethanol taking precautionary measures to avoid mix-up of samples on the basis of animals and collection sites as tubes were properly labelled and were stored at $4{ }^{\circ} \mathrm{C}$ until further processing [8]. All tick species collected were identified using morphological criteria and appropriate taxonomic keys [12]. Ticks genders and feeding states were not taken into consideration as they do not affect their ability to transmit pathogens.

\subsection{Total Genomic DNA Extraction from Ticks}

Prior to DNA extraction, the preserved specimens were washed with sterile distilled water and left to dry in a sterile Petri dish. This was done in order to remove all the ethanol residues from the tick samples which might negatively affect the downstream PCR reactions. The ticks were singly crushed with sterile glass rod in Petri dishes based on their morphological delineations and processed separately for DNA extraction using ReliaPrep DNA Tissue miniprep system ZYMORESEARCH (Zymo Research Corporation, Irvine, California, CA, USA) Quick DNA Universal Kit according to the manufacturer's instruction. The adult ticks were processed separately while the nymphs of the same species collected from the same animal were pooled together and processed for DNA extraction. All ticks processing and PCR reactions were performed in biosafety cabinet which were always left sterile overnight using UV light. Absolute precautionary measures were adopted to avoid cross contaminations of reagents, blades and instruments used throughout the process. Commercially certified DNA/RNase free filter barrier tips were used to prevent aerosol contamination while all PCR setup was performed in a hood far from DNA isolation area.

\subsection{Molecular Identification of Tick and Detection of Bacteria in Ticks}

The morphologically identified ticks were confirmed molecularly and profiled for genetic evidence of rickettsial DNAs using the primer pairs in Table 1. These primer pairs have been used in the species identification of Rickettsia pathogens as previously reported by Regnery et al. [13], Eremeeva and Raoult [14], and Kollars and Kengluecha [15] as adapted by Williamson et al. [16]. PCR mixtures and cycling profiles were as previously described by the authors.

\subsection{DNA Sequencing, Sequence Editing and BLASTn Search}

The amplified PCR products were sequenced in a commercial sequencing facility using the dideoxynucleotide chain termination approach on an ABI PRISM Genetic Analyzer (ABI Prism310, Applied Biosystems, Foster City, CA, USA). Alignment and sequence editing was achieved using Geneious R10 version. Generated nucleotide sequences were compared with those representative of the rickettsial strains and available in the GenBank database. Rickettsial sequences that had above $97 \%$ homology with test samples were used as reference strains for phylogenetic analyses along with other curated representatives of SFGR sequences in GenBank database. 
Table 1. Primer sequences used in the molecular identification of ticks and Rickettsia spp.

\begin{tabular}{cccccc}
\hline & Primer Name & Gene Primer Sequence $\mathbf{( 5}^{\prime}$ to $\mathbf{3}^{\prime} \mathbf{)}$ & Amplicon bp & TM & Ref \\
\hline \multirow{2}{*}{ Tick DNA } & 85F & 12S TTAAGCTTTCAGAGGAATTTGCTC & 110 & 54.0 & {$[12]$} \\
& 225R & 12S TTTWWGCTGCACCTTGACTTAA & & 52.7 & \\
\hline & Rr.190 70P & rompA ATGGCGAATATTTCTCCAAAA & 610 & 52.5 & {$[13]$} \\
& Rr.190 602N & rompA AGTGCAGCATTCGCTCCCCCT & & 64.9 & \\
Rickettsia spp. & BG1-21 & rompB GGCAATTAATATCGCTGACGG & 511 & 55.6 & {$[14]$} \\
& BG2-20 & rompB GCATCTGCACTAGCACTTTC & & 55.2 & \\
& RrCS372 & gltA TTTGTAGCTCTTCTCATCCTATGGC & 410 & 59.0 & {$[15]$} \\
& RrCS989 & gltA CCAAGTTCCTTTAATACTTCTTTGC & & 57.4 & \\
\hline
\end{tabular}

$\mathrm{Bp}=$ base pair, $\mathrm{spp}=$ species $\mathrm{TM}=$ melting temperature.

\subsection{Phylogenetic Analysis}

Edited sequences were used to construct a maximum possible phylogenetic tree using Mega 7 version software (PENN, State College, Pennsylvania, PA, USA) with 1000 bootstrap replicate. Phylogenetic trees were constructed using BioEdit Tree Builder. Sequence data sets of positive samples were submitted to NCBI GenBank for accession numbers.

\section{Results}

\subsection{Tick Prevalence within the Two Study Sites}

Out of 953 ticks, 60 (6.3\%) resulted positive by targeting the ompA and $о m p B$ genes. Only 43 samples out of the 60 positive ompA amplicons were sequenced due to some technical constraints. All the positive $о m p$ B amplicons were sequenced as well as representatives of tick's $12 \mathrm{~S}$ rDNA amplicons while none was sequenced for the $g l t \mathrm{~A}$ positive amplicons. The inability to sequence the $g l t \mathrm{~A}$ amplicons was due to financial constraints coupled with the fact that it has lower discriminatory power to delineate Rickettsia spp.

Identification methods used to delineate the collected ticks showed that they belonged to three genera, which were Rhipicephalus, Amblyomma and Hyalomma with six different species. Amongst them were $A$. hebraeum $39.14 \%(\mathrm{n}=373$ adult), R. appendiculatus $16.4 \%(\mathrm{n}=156(34)$ adult $)$, R. microplus $13.96 \%$ ( $\mathrm{n}=133$ adult), R. simus.11.75\% ( $\mathrm{n}=112$ adult), H. truncatum $9.76 \%(\mathrm{n}=93$ adult) and Rhipicephalus eversti $9.02 \%$ ( $\mathrm{n}=86$ adult) in decreasing order of their prevalence. A. hebraeum was the most prevalent species in both study sites with cattle serving as the common host.

Furthermore, BLAST analysis of the edited tick $12 \mathrm{~S}$ mitochondrial rDNA sequences showed that they all had more than $97 \%$ sequence homology with curated ticks' sequences in GenBank. Molecular confirmation of the representatives of different ticks delineated by morphological methods showed the accuracy of the morphologic classification as shown in Figure 1. The proportions of the different ticks collected in the two study sites are presented in Table 2 while Table 3 is the list of reference sequences obtained from GenBank that were used in the phylogenetic analysis of the ticks' sequences generated in this study.

The cladogram was constructed by using the neighbour-joining method in ClustalX 2.1 program (University College Dublin, Dublin, Ireland). Test sequences intermingled with sequences of Amblyomma, Hyalomma, and Rhipicephalus species reference strains obtained from GenBank. All sequenced ticks samples clustered with the three identified genera; Amblyomma, Hyalomma and Ripicephalus reference sequences obtained from GenBank. Test sequences are in bracket and arrowed while the reference sequences are in GenBank accession number. 


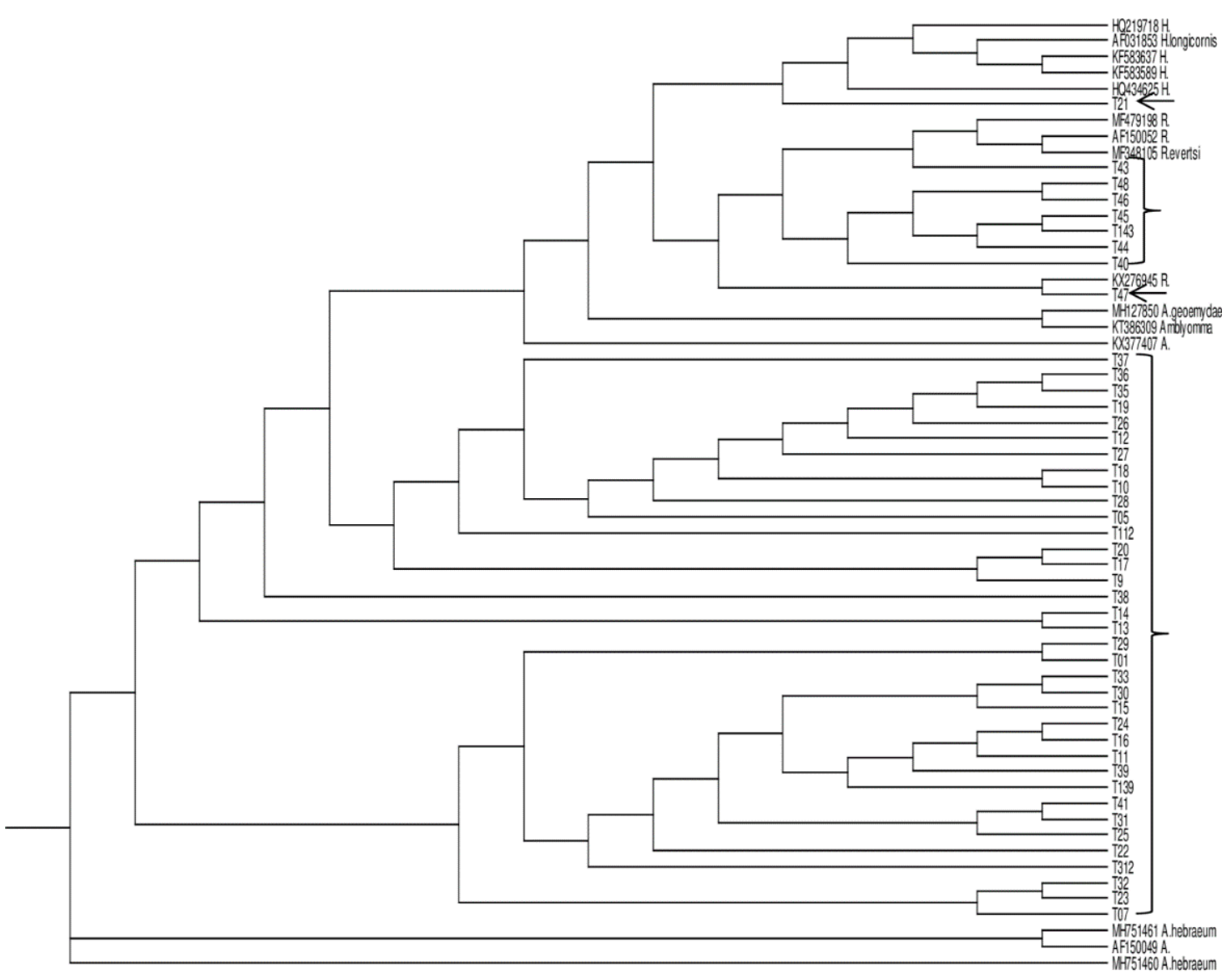

Figure 1. Neighbour-joining rectangular cladogram of $12 \mathrm{~S}$ mitochondrial rDNA of tick species generated from the study with the reference sequences from GenBank.

Table 2. Proportion and distribution of collected tick species in Debe Location and Fort Beaufort, geographical coordinates: $32.836^{\circ} \mathrm{S}, 27.154^{\circ} \mathrm{E}$, coordinates $32^{\circ} 47^{\prime} 0^{\prime \prime} \mathrm{S}, 26^{\circ} 38^{\prime} 0^{\prime \prime} \mathrm{E}$.

\begin{tabular}{|c|c|c|c|c|}
\hline Animals & Tick Species & Developmental Stage & Number of Ticks & Rickettisa Positive Samples \\
\hline \multirow[t]{6}{*}{ CATTLE } & R. eversti & Adult & 77 & 5 \\
\hline & A. hebraeum & Adult & 170 & 25 \\
\hline & R. microplus & Adult & 27 & \\
\hline & R. appendiculatus & Adult & 94 & 3 \\
\hline & R. simus & Adult & 67 & \\
\hline & H. truncatum & Adult & 55 & \\
\hline \multirow[t]{6}{*}{ GOAT } & R. eversti & Adult & 0 & \\
\hline & A. hebraeum & Adult & 133 & 12 \\
\hline & R. microplus & Nymph & 79 & \\
\hline & R. simus & Adult & 24 & \\
\hline & H. truncatum & Adult & 20 & \\
\hline & R. appendiculatus & Adult & 62 & 2 \\
\hline \multirow[t]{5}{*}{ SHEEP } & R. eversti & Adult & 9 & 9 \\
\hline & A. hebraeum & Adult & 65 & 4 \\
\hline & R. microplus & Adult & 27 & \\
\hline & R. simus & Adult & 21 & \\
\hline & H. truncatum & Adult & 18 & \\
\hline HORSE & A. hebraeum & Adult & 25 & \\
\hline
\end{tabular}


Table 3. Reference tick strains used in phylogenetic analysis.

\begin{tabular}{ccc}
\hline Strain Accession Number & Species & Geographical Origin \\
\hline KU284929 & A. trigrinum & Brazil \\
KU284920 & A. triste & Uruguay \\
KU284864 & A. parvitarsum & Argentina \\
KY676832 & R. annulatus & Israel \\
KY676839 & R. australis & South Africa \\
MF479198 & R. evertsi & DRC \\
AF150043 & Boophilus & Jordan \\
EU921766 & R. microplus & Mozambique \\
KU568502 & R. geigyi & Guinea-Bissau \\
MK332391 & R. microplus & Uganda \\
MG076938 & A. maculatum & Mexico \\
KX377407 & A. gemma & Ethiopia \\
AF150049 & A. hebraeum & Zimbabwe \\
AF031865 & R. punctatus & Australia \\
\hline
\end{tabular}

\subsection{Prevalence of Rickettsia spp in the Study Sites}

Rickettsial DNA fragments were obtained from the three genera of ticks collected in the study sites with more detected in A. hebreaum. In addition, a higher proportion of the pathogens (55\%) were detected in ticks collected from cattle, $23 \%$ prevalence in ticks from goats while that of sheep was $22 \%$. There were no clinical or pathological indicators of disease observed in the animals.

A homology search for the generated Rickettsia sequences showed that they had a high sequence similarity of above $97 \%$ homology with sequences of Rickettsia spp. in GenBank database. Comparison of the $43 \mathrm{omp} A$ and $60 \mathrm{ompB}$ sequences by BLAST analysis showed that majority of the sequences were $\geq 98 \%$ homologous with R. africae while only two samples (B188) and B209 had 99\% similarity with R. parkeri (KY113111) and 100\% homologous with R. tamurae (DQ113910), respectively, based on omp B BLASTn analysis. However, discordances in homology between ompA and ompB sequences of the two samples were observed as shown in Figures $2 \mathrm{a}-\mathrm{d}$ and $3 \mathrm{a}-\mathrm{d}$ respectively. The ompA of sample 188 showed 99\% similarity with Candidatus Rickettsia (EU272186) while the ompB of the same sample was $100 \%$ homologous to $R$. parkeri (KY113111) in both amino acid and nucleotide sequences alignments. Similarly, A209 of sample 209 was 100\% homologous with R. africae (EU622980) while B209 of the same sample was $100 \%$ homologous with $R$. tamurae (DQ113910) respectively in both amino acid and nucleotide sequences alignments.

Reference sequences used for phylogenetic analyses were randomly selected and analyzed with generated study sequences of $\operatorname{omp} \mathrm{A}$ and $\operatorname{omp} \mathrm{B}$ genes. The phylogenetic tree obtained for $о m p A$ gene showed that test sequences clustered with reference sequences from NCBI GenBank nucleotides database as illustrated in Figure 4. Majority of the ompA sequences clustered with R. africae (U43790; KJ645933, GU247115, MG515014) with bootstrap values above 81\% while sequences A196 and A198 clustered equidistance between $R$. tamurae (LC388791) R. africae (CP001612) with 92\% bootstrap reliability and A188 and A208 clustered with Candidatus Rickettsia EU272186 with 77\% bootstrap value as shown in Figure 4 while the phylogenetic tree constructed with $o m p$ B sequences is shown in Figure 5 with bootstrap values above $70 \%$. Phylogenetic analyses of the $\operatorname{omp} \mathrm{A}$ and $o m p \mathrm{~B}$ sequences support the observed discrepancies in homology. Sequence B150 clustered between R. rhipicephali (AF123719) and R. parkeri (KY113111) phylogenetically but a BLAST search showed it as having close homology with uncultured Rickettsia clone and R. conorii (FJ015092) by 76\% respectively.

\subsection{GenBank Accession Numbers}

Sequences obtained in this study have been deposited in the GenBank database under the following accession numbers: MK347206-MK347212 (tick identification), MK405447-MK405477 (rickettsia ompA gene), MK405386-MK405446 (rickettsia omp B gene). 
(a)

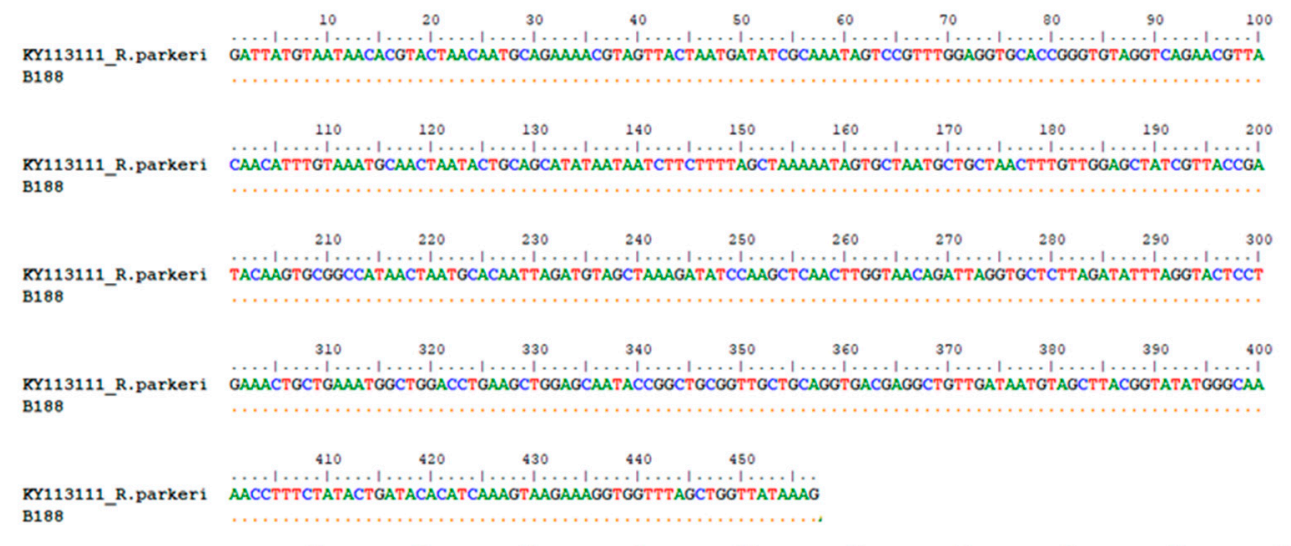

(b)

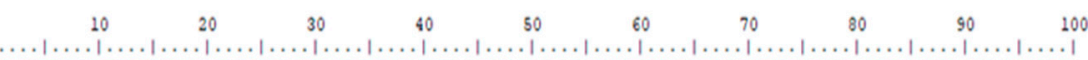
KY113111_R.parkeri DYVITRTNNAENVVTNDIANSPFGGAPGVQNVTTFVNATNTAYYNNLLLARNSANAANEVGAIVTDTSAAITNAQLDVARDIQAQLGNRLALRYLGTP B188

(c)
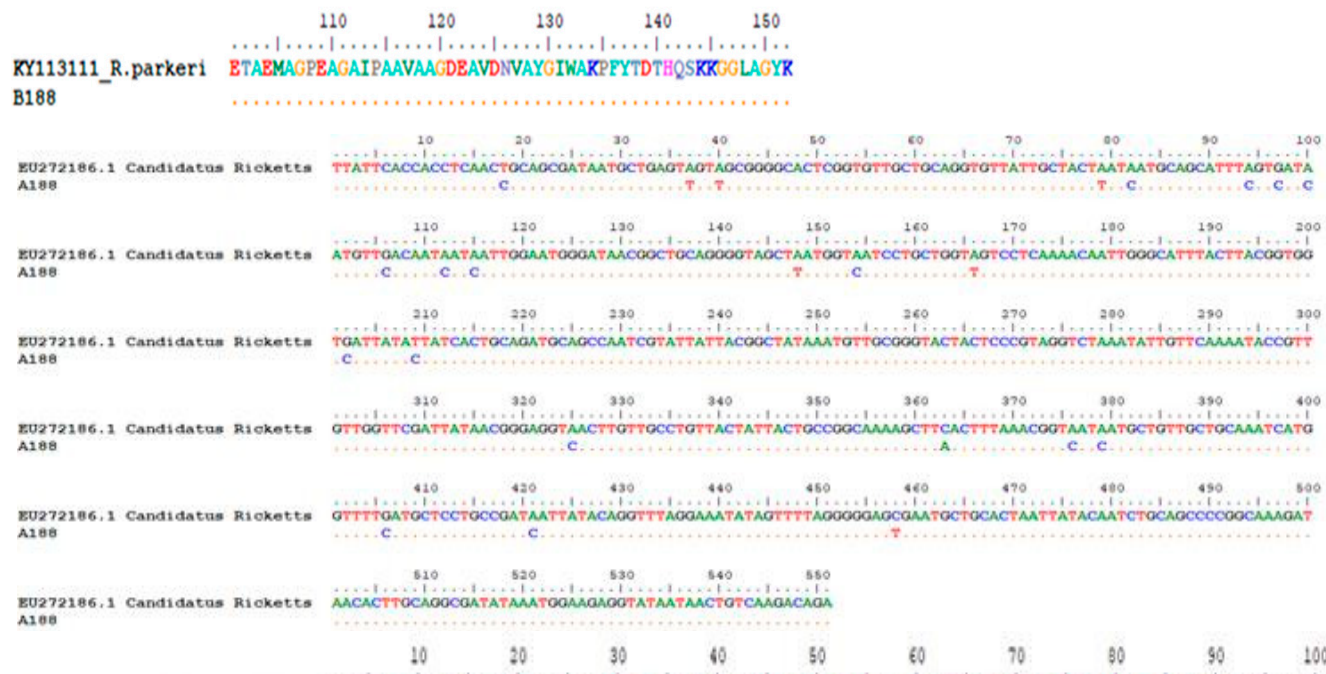

80272186.1 Candidatus Ricketts A188

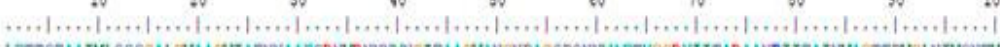

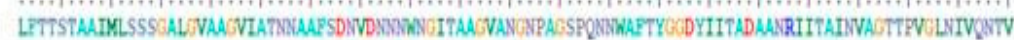

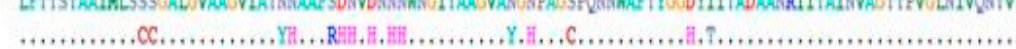

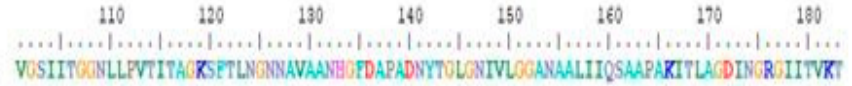

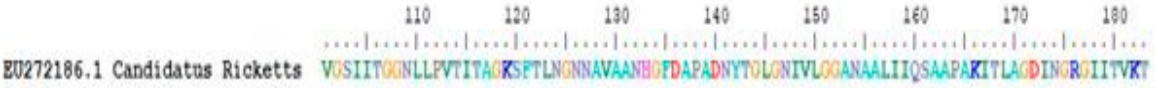
A188

Figure 2. (a) Nucleotide sequence alignment of the ompB gene of sample B188 against the homologous reference sequence of $R$. parkeri (KY113111) indicating 100\% homology. Reference sequence was obtained based on highest percentage homology that the test sequence has with $R$. parkeri which was obtained through Nucleotide BLAST tool in the GenBank. The dots represent nucleotide similarity of the query sequence with the reference strain. (b) Amino acid sequence alignment of the ompB gene of sample B188 against the homologous reference sequence of R. parkeri (KY113111) indicating $100 \%$ homology. Reference sequence was obtained based on highest percentage homology that the test sequence has with $R$. parkeri which was obtained through Nucleotide BLAST tool in the GenBank. The dots represent amino acid similarity of the query sequence with the reference strain. (c) The degree of homology between test sequence A188 and Candidatus Rickettsia (EU272186.1) reference strain: Nucleotide sequence alignment of the ompA gene of sample A188 against the homologous reference sequence of Candidatus Rickettsia sp. (EU272186.1) indicating 95\% homology. The dots represent nucleotide similarity of the query sequence with the reference strain. (d) Amino acid alignment of the ompA gene of sample A188 against the homologous reference sequence of Candidatus Rickettsia sp. (EU272186.1) indicating 95\% homology. The dots represent amino acid similarity of the query sequence with the reference strain. 
(a)

(b)
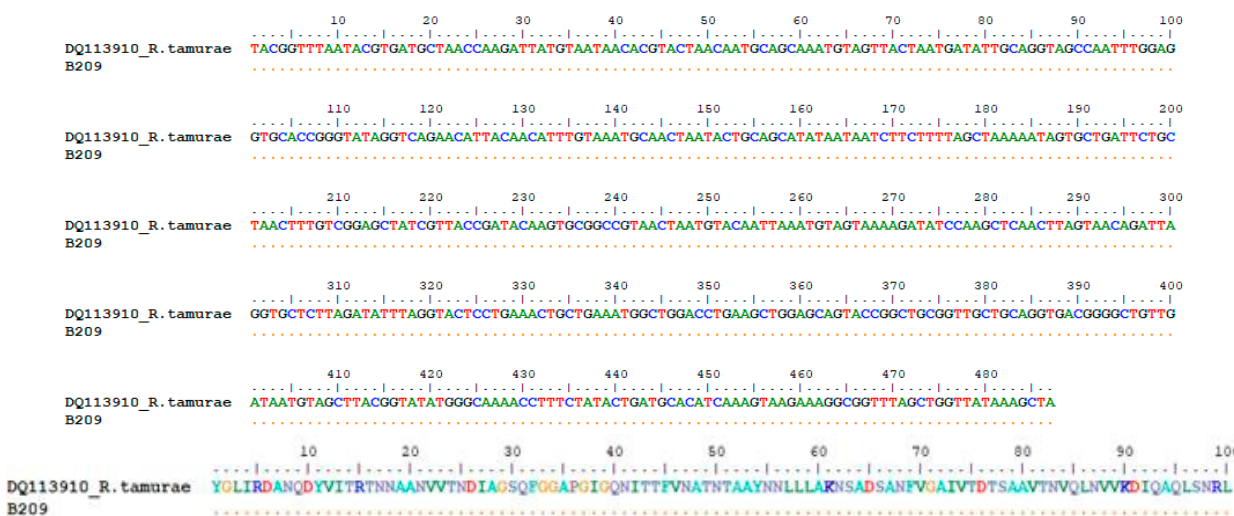
$110 \quad 120 \quad 130 \quad 140 \quad 150 \quad 160$

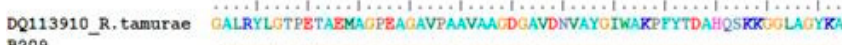

(c)

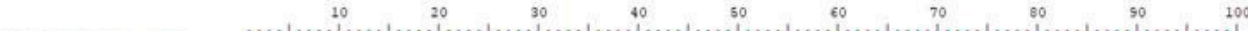

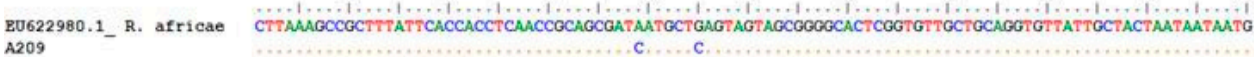

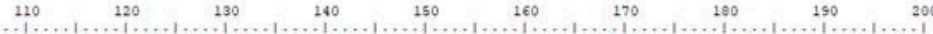

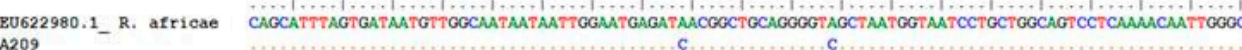

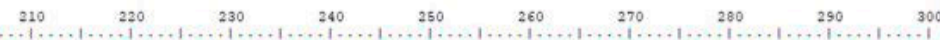
EU622980.1_ R. africae ATTACTTACGGGGTGATATACTATCACTGCAGATGCAGCCGATCGTATTATTACGGCTATAMTGTTOCAGGTACTACTCCOGTAGGTCTAATATT

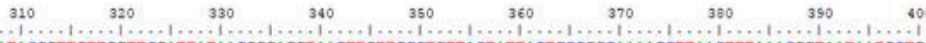

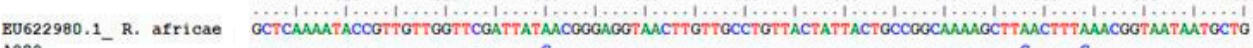
A209

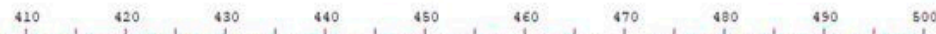

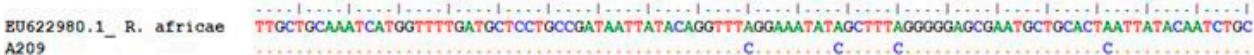
$510 \quad 520 \quad 530 \quad 540 \quad 550 \quad 560 \quad 570$

(d)

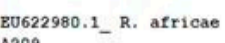

Figure 3. (a) Nucleotide sequence alignment of the ompB gene of sample B209 against the homologous reference sequence of $R$. tamurae (DQ113910) indicating 100\% homology. Reference sequence was obtained based on highest percentage homology that the test sequence has with $R$. tamurae which was obtained through Nucleotide BLAST tool in the GenBank. The dots represent nucleotide similarity of the query sequence with the reference strain. (b) Amino acid sequence alignment of the ompB gene of sample B209 against the homologous reference sequence of $R$. tamurae (DQ113910) indicating $100 \%$ homology. Reference sequence was obtained based on highest percentage homology that the test sequence has with $R$. tamurae which was obtained through Nucleotide BLAST tool in the GenBank. The dots represent amino acid similarity of the query sequence with the reference strain. (c) The degree of homology between test sequence A209 and R. africae (EU622980.1) reference strain: Nucleotide sequence alignment of the ompA gene of sample A209 against the homologous reference sequence of $R$. africae (EU622980) indicating high homology with R. africae whereas the ompB gene of the same sample has $100 \%$ identity with $R$. tamurae. The dots represent nucleotide similarity of the query sequence with the reference strain. (d) Amino acid sequence alignment of the ompA gene of sample A209 against the homologous reference sequence of $R$. africae (EU622980). The dots represent amino acid similarity of the query sequence with the reference strain. 


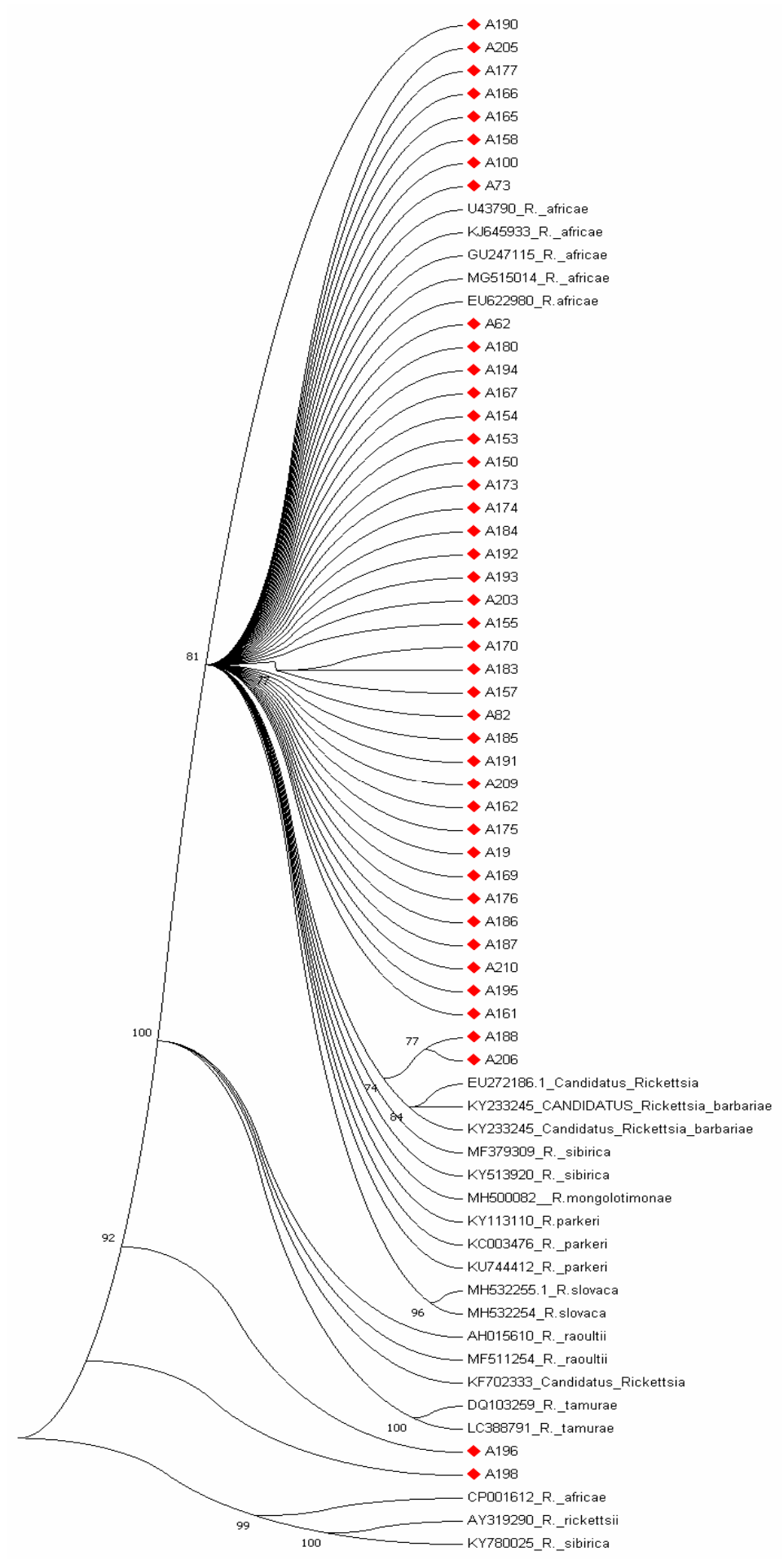

Figure 4. Phylogenetic tree of ompA gene sequences in bold red generated from the study with the related reference sequences obtained from NCBI GenBank. The evolutionary history was inferred using the neighbor-joining method [17]. The optimal tree with the sum of branch length $=1.67432413$ is shown. The percentage of replicate trees in which the associated taxa clustered together in the bootstrap test (1000 replicates) is shown next to the branches [18]. The evolutionary distances were computed using the p-distance method [19] and are in the units of the number of base differences per site. The analysis involved 67 nucleotide sequences. Codon positions included were $1 \mathrm{st}+2 \mathrm{nd}+3 \mathrm{rd}$ + Noncoding. All positions containing gaps and missing data were eliminated. There were a total of 166 positions in the final dataset. Evolutionary analyses were conducted in MEGA7 [20]. The test sequences denoted diamond red clustered with other Rickettsia references. 


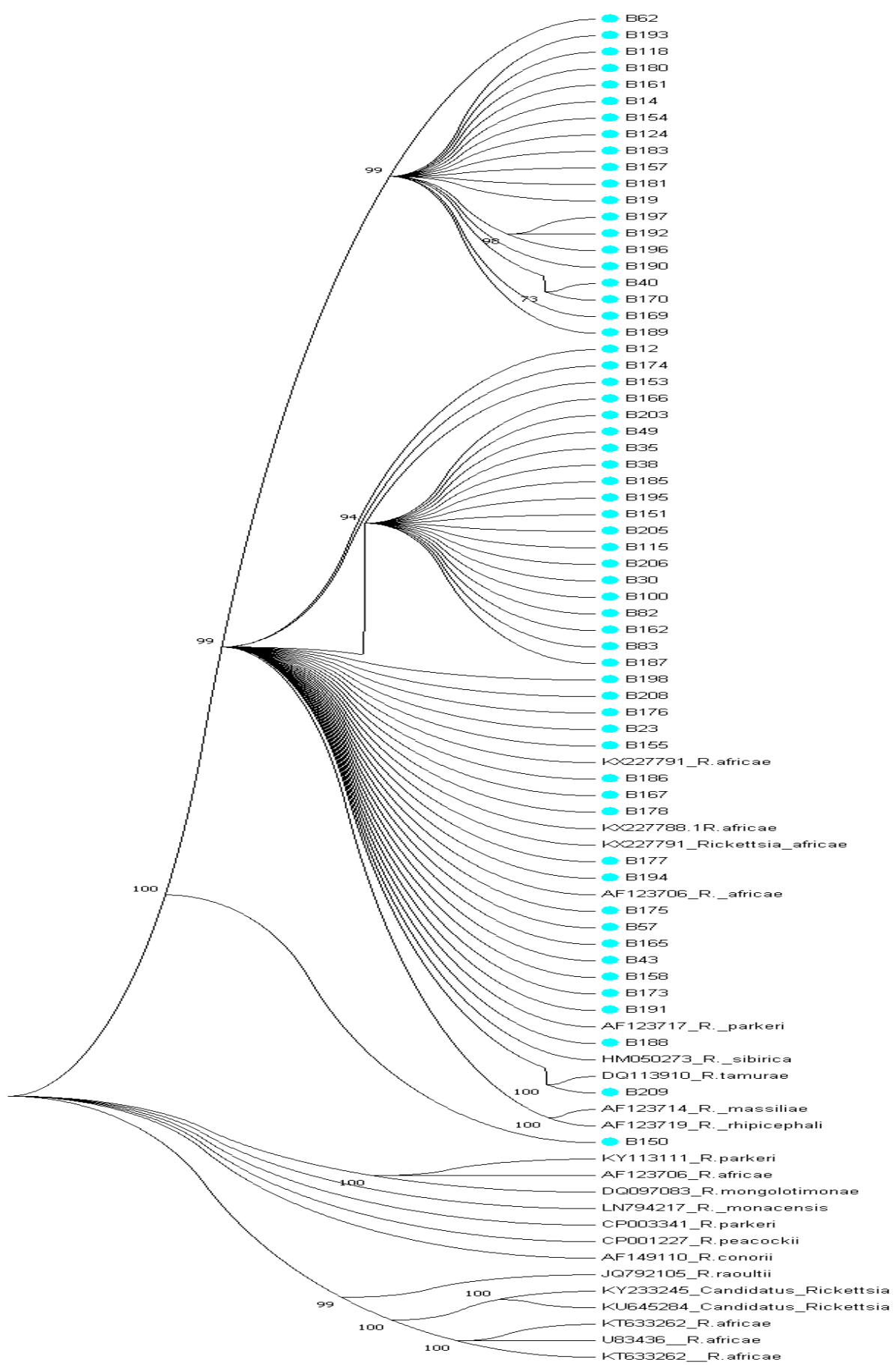

Figure 5. Phylogenetic tree of $o m p B$ gene sequences in bold generated from the study with the related reference sequences obtained from NCBI GenBank. The evolutionary history was inferred using the neighbor-joining method [17]. The optimal tree with the sum of branch length $=2.89828155$ is shown. The percentage of replicate trees in which the associated taxa clustered together in the bootstrap test (1000 replicates) is shown next to the branches [18]. The evolutionary distances were computed using the p-distance method [19] and are in the units of the number of base differences per site. The analysis involved 86 nucleotide sequences. Codon positions included were $1 \mathrm{st}+2 \mathrm{nd}+3 \mathrm{rd}+$ Noncoding. All positions containing gaps and missing data were eliminated. There were a total of 236 positions in the final dataset. Evolutionary analyses were conducted in MEGA7 [20]. All study sequences clustered phylogenetically with $R$. africae sequences from GenBank with the exception of sequences B188 and B209; B188 clustered with R. parkeri (AF123717) while sample B209 clustered with R. tamurae (DQ113910) with high bootstrap values above $99 \%$. Test sequences are in bold in blue dot. 


\section{Discussion}

Spotted fever group rickettsiae (SFGR) are emerging infectious diseases with global distribution that are caused by bacteria of the genus Rickettsia. These zoonotic diseases are transmitted by ticks' vectors among wild and domestic animals [21]. Domestic animals and humans are accidental dead end hosts. Currently, the genes encoding two surface proteins, romp $\mathrm{A}$ and $\operatorname{romp} \mathrm{B}$ are used in the delineation of SFGR members. Fournier et al. [22] proved the usefulness of these genes for taxonomic purposes when they demonstrated the valid description of two new rickettsial species $R$. felis and R. peacockii. According to Fournier et al. [22] the presence of an ompA gene warrants classification of a rickettsial isolate into the spotted fever group along with $\operatorname{omp} \mathrm{B}$ gene with a homology of $85.8 \%$.

DNAs of $R$. africae, $R$. parkeri and R. tamurae belonging to SFGR were detected amongst the ticks genera collected in this study. These three species are closely related and they are the etiologic agents of African and American tick bites fever that are very prevalent in the sub-Saharan African, United States of America and Brazil and rickettsiosis in Japan, respectively [3]. R. africae, the etiologic agent of African tick bite fever is generally transmitted by Amblyomma ticks to humans and its natural reservoir is wild rodents [3].

Even though rickettsial diseases are found globally, there is no one single tick-borne rickettsial diseases that is found all over the world, rather they are restricted to geographical regions, where designated transmitting ticks exist. The majority of the populace living in sub-Saharan Africa might be seropositive for R. africae, hence they hardly succumb to African tick bite fever as opposed to travelers to endemic regions of Africa. Sero-prevalence of $R$. africae in Cameroon is between 11.9-51.8\% while in Senegal, it ranges between 21.4-51\% [23-25]. In a group of 940 travelers to South Africa, majority $(27 \%)$ of them had flu-like symptoms as a result of contracting R. africae, the etiologic agent of African tick-bite fever, occasioned by their travels [26] reported a seroprevalence of $51.7 \%$ among inpatients identified with febrile fever who were tested for acute SFGR and Typhus Group Rickettsioses TGR in Moshi, Tanzania.

The majority of data on African tick bite fever ATBF cases, documented to date have been obtained from tourists returning from endemic countries, such as Botswana, South Africa, rural sub-Equatorial Africa, and Zimbabwe [3,26-29]. Bogovic et al. [3] reported a case of ATBF in a Slovenian traveler returning from Uganda. The 29-year-old man who had no previously known underlying illnesses sought care after returning from a two weeks visit to Uganda for fever, chills, pains and complained of a tick bite a day prior to departing the country. Lorusso et al. [30] were the first people to report about $R$. africae in ticks in Uganda where R. conorii had previously been reported by Socolovschi et al. [29] as being prevalent. Similarly, Angerami et al. ([31] reported ATBF in a Brazilian who visited South Africa upon his return to Brazil. He had eschar and symptoms characteristics of ATBF which was confirmed by both immunological and molecular diagnostic methods to be infected by $R$. africae. African tick bite fever have also been reported for the first time by Harrison et al. [32] on an Austrian traveler to East Africa who acquired the disease through tick bite during a visit to Tanzania. ATBF is generally a mild disease and to date, there has not been any reported deaths attributed to infection of $R$. africae. However, just like R. parkeri rickettsiosis, the disease caused by $R$. africae is often associated with an inoculation eschar at the spot of attachment of the tick vector. Usually, the symptoms associated with ATBF normally appear many days after the development of the eschar and they are usually that of fever, headache, myalgia, regional lymphadenopathy and generalized rash in about $50 \%$ of the cases.

The Amblyomma variegatum tick has been reported to be the vector of $R$. africae with a prevalence of 97.1\% in Uganda [33]. However, Waner et al. [34] reported finding the DNA of R. africae in Hyalomma detritum tick collected from a wild boar in Israel indicating that the spotted fever group rickettsia is not limited in distribution to the African continent nor to a given host tick. Similarly, Yssouf et al. [35] reported the detection of $R$. africae in $90 \%$ of A. variegatum, $1 \%$ of $R$. appendiculatus and $2.7 \%$ of Rhipicephalus (Boophilus) microplus in study ticks collected from locally domesticated animals in the Union of the Comoros, as well as in $77.14 \%$ in A. variegatum ticks obtained from cattle imported into the country. In addition, Maina et al. [36] reported the detection of R. africae-genotype DNA in $92.6 \%$ of adult 
A. variegatum ticks collected from domestic ruminants in Kenya even though they found no evidence of the pathogen in blood specimens in the domestic animals sampled. R. africae genetic materials have been detected by PCR from different species of ticks belonging to Amblyomma, Rhipicephalus, Hyalomma genera in several African countries such as Mali, Senegal, Guinea, Liberia, Sudan, Democratic Republic of Congo, Cameroon, Nigeria, Niger, Kenya, Cote di'voire and Burundi $[1,3,37]$ and these reports are in consonant with our finding as the DNA of $R$. africae was detected in the different genera of ticks that we assessed.

R. parkeri, a member of the spotted fever group rickettsia, is the etiologic agent of American tick bite fever that is prevalent in the South and North American continents and it is transmitted by the Amblyomma species. The spotted fever disease associated with the organism is characterized by eschar related ailments in humans which are similar to symptoms of Rocky Mountain spotted fever. The index rickettsiosis spotted fever case caused by R. parkeri was first recognized by Paddock et al. [38] and ever since then; numerous cases have been identified and reported in many southeastern states of the USA [39,40]. Cowdry, [41], was the first to describe the finding of the organism in the tissues and eggs of female A. maculatum ticks that were collected in Jackson County, Missouri. However, Parker et al. [42] isolated the organism for the first time from Gulf Coast ticks that were collected in South eastern Texas and ever since then, $R$. parkeri a SFG rickettsiae has been frequently detected in A. maculatum. R. parkeri has however been detected in other tick species other than A. maculatum as Williamson et al. [16] reported the detection of its DNA in D. variabilis in ticks removed from persons in Texas, USA. R. parkeri infections in dogs and cows have been described in southeastern United States. Infection of humans by R. parkeri in most cases is associated with a necrotic eschar at the point of inoculation after several days of an infected tick bite and it is usually with a low grade to moderate fever that is very similar to Rocky Mountain spotted fever (RMSF)though less in severity. Some of the symptoms associated with $R$. parkeri rickettsioses are fever, inoculation eschar, macules or papules rashes, vesicles or pustules, petechiae on palms or soles, headache, myalgias, sore throat, lymphadenopathy, diarrhea, nausea or vomiting [40]. No case of $R$. parkeri rickettsiosis has however been reported in Central America but $A$. maculatum is widely distributed throughout the region and a mild eschar-related rickettsiosis that is very akin to $R$. parkeri rickettsiosis has been reported in a traveler who returned from Honduras [43]. Since the first human disease case caused by $R$. parkeri was documented by Paddock et al. [38] numerous cases of rickettsioses caused by $R$. parkeri have been reported among persons residing in the ecological range of the vector tick, A. maculatum, in the USA. Infections and eschar associated illness with $R$. parkeri have been frequently reported in several Latin American countries such as Argentina, Brazil, and Uruguay, and the organism has been detected in A. triste ticks [44,45]. For the first time, here we report the detection of genetic material of $R$. parkeri in the African continent and the epidemiological implications are not well known. However, because it has been documented as a human pathogen, its involvement in human cases in the study sites may not be unlikely as it may probably have gone undetected. We observed discordant phylogenetic assignments of the ompA and $о m p$ B genes of sample 188 as they were found to cluster with Candidatus_Rickettsia EU27216.1 and R. parkeri KY113110 respectively in Figures 4 and 5 and this was shown to be so with nucleotide and amino acid alignments as shown in Figure 2a-d.

Rickettsia sp. strain Ga-Seema is an incompletely described rickettsial that was detected from three fed adult male Rhipicephalus simus ticks collected from two donkeys in 2014 in Hlahlagane, Limpopo Province, South Africa by Halajian et al. [46] which has not been reported previously and its pathogenic potential is currently unknown.

$R$. tamurae infection according to Imaokaa et al. [47] is associated with symptoms such as mild local inflammatory signs like swellings, erythema, redness heat and pain. Symptoms of $R$. tamurae infection mimics cellulitis with increased serum titers of antibody against the organism [48]. Unlike most SFGR, infections with $R$. tamurae are not associated with high fever, generalized rash, lymphadenopathy as it is often seen in other spotted fever rickettsioses. R.tamurae was first isolated from A. testudinarium ticks in Japan and has the wild boar and domestic pigs as it primary host although it can also infest 
deer, cattle, other ungulates and domestic livestock as well as humans [47-49]. R. tamurae has been isolated from the skin biopsy specimen from wild boars and also in ticks [47]. It was previously thought to be non-pathogenic to humans until it was reported in human cases in Japan as well as in Laos where its involvement in spotted fever case was documented after a patient tested seropositive for the organism [50]. Phylogenetic analyses of the ompA and $\operatorname{ompB}$ sequences of sample 209 assigned them as R. africae and R. tamurae, respectively, and homology search confirmed that ompA sequence is $R$. africae while the $\operatorname{omp} \mathrm{B}$ sequence had $100 \%$ similarity with $R$. tamurae. We performed nucleotide and amino acid sequences alignments with the two sequences as shown in Figure $3 a-d$, the omp $B$ showed complete homology with $R$. tamurae indicating that sample B209 is most highly $R$. tamurae in the ompB gene region while the $\operatorname{ompA}$ was closely related with $R$. africae. We are not sure if recombination did occur in the two genes in question. Further study, like full genome sequencing, is needed to elucidate this observation. R. tamurae has been associated with different Amblyomma spp. as reported by Blanco et al. [51] who detected the pathogen in screened nymphs of $A$. ovale tick collected from small mammals such as wild rodents and marsupials in Brazil while a recent report stated its detection in a Haemaphysalis megaspinosa tick [51]. However, this is the first report of $R$. tamurae-like pathogen, the agent of SFG rickettsiosis in Japan and some Far East Asian countries in A. variegatum tick collected from cattle in the African continent.

\section{Conclusions and Recommendations}

We have reported on the detection of tick-borne rickettsia pathogens which are the etiologic agents of spotted fever group rickettsioses. The findings of the DNA of $R$. africae, $R$. parkeri and R. tamurae in the three genera of ticks collected in this study are of clinico-epidemiological significance and merits further investigations. The discordance of the $\operatorname{omp} \mathrm{A}$ and $о т p \mathrm{~B}$ gene fragments of the same samples is noteworthy and a full genome sequencing or a complete $\operatorname{omp} \mathrm{A}$ and $\operatorname{omp} \mathrm{B}$ is, therefore, warranted. Usually, the SFGR are not considered in the diagnosis and treatment of patients with signs and symptoms of fever in these rural communities. This data is therefore a wakeup call on health care personnel to consider infections caused by these pathogens as they may probably be responsible for the flulike symptoms presented by their patients. Education and awareness campaigns in rural communities on the implications of tick bites, control strategies for ticks, including seeking medical attention for tick bites, should be mounted.

\section{Endnote}

GenBank Accession numbers of Rickettsia reference sequences used in phylogenetic analyses of the ompA and ompB genes

OMPB

DQ113910_R.tamurae, CP003341_R.parkeri, AF123706_R.africae, KX227791_R.africae, AF149110_R.conorii, KX227788_R.africae, KY113111_R.parkeri, LN794217_R. monacensis, CP001227_R.peacockii, JQ792105_R.raoultii, U83436_R.africae, KY233245_Candidatus Rickettsia, AF123714_R. massiliae, AF123719_R. rhipicephali, HM050273_R. sibirica, KU645284_Candidatus Rickettsia, KT633262_R.africae, DQ097083_R. mongolotimonae, KX227791_R. africae, KT633262.1 R.africae, KY113111_R_parkeri, AF123706_R. africae, AF123717_R. parkeri

OmpA

CP001612_R. africae, AH015610_R. raoultii, AY319290_R. rickettsia, KF702333_Candidatus Rickettsia, KY780025_R. sibirica, EU272186_Candidatus Rickettsia, MF511254_R. raoultii, MH500082_R. mongolotimonae, MH532255_R.slovaca, KY113110_R.parkeri, KY233245_CANDIDATUS Rickettsia barbariae, MF379309_R. sibirica, KY513920_R. sibirica, EU622980_R.africae, MH532254_R.slovaca, MG515014_R. africae GU247115_R. africae, KJ645933_R. africae, U43790_R. africae, DQ103259_R. tamurae, LC388791_R. tamurae, KC003476_R. parkeri, KU744412_R. parkeri

Author Contributions: The study was designed by B.C.I. The sampling, laboratory work and bioinformatic analyses and write-up were carried out by B.C.I., A.N., while B.C.I. and C.L.O. supervised the study and 
contributed to the interpretation of the data, manuscript editing and approval of the final manuscript. All authors have read and agreed to the published version of the manuscript.

Funding: South African Medical Research Council https://www.samrc.ac.za/ Grant number RDG2017/18 and the APC was funded by Sefako Makgatho Health Sciences University https://www.smu.ac.za/. Check carefully that the details given are accurate and use the standard spelling of funding agency names at https://search.crossref.org/ funding, any errors may affect your future funding.

Acknowledgments: We thank the farmers who allowed us access into the farms for sample collection and for their assistance in sample collection.

Conflicts of Interest: All authors declare no conflicts of interest.

Data Availability Statement: The data that support the findings of this study are openly available in [GenBank] at https://www.ncbi.nlm.nih.gov/nuccore, MK347206-MK347212 (tick identification), MK405447-MK405477 (rickettsia ompA gene), and MK405386-MK405446 (rickettsia ompB gene).

\section{References}

1. Parola, P.; Paddock, C.D.; Socolovschi, C.; Labruna, M.B.; Mediannikov, O.; Kernif, T.; Abdad, M.Y.; Stenos, J.; Britam, I.; Fournier, P.-E.; et al. Update on Tick-Borne Rickettsioses around the World: A Geographic Approach. Clin. Microbiol. Rev. 2013, 657-702. [CrossRef] [PubMed]

2. Raoult, D.; Roux, V. Rickettsioses as paradigms of new or emerging infectious diseases. Clin. Microbiol. Rev. 1997, 10, 694-719. [CrossRef] [PubMed]

3. Bogovic, P.; Lotric-Furlan, S.; Korva, M.; Avsic-Zupanc, T. African Tick-Bite Fever in Traveler Returning to Slovenia from Uganda. Emerg. Infect. Dis. 2016, 22. [CrossRef] [PubMed]

4. Shpynov, S.N.; Fournier, P.E.; Pozdnichenko, N.N.; Gumenuk, A.S.; Skiba, A.A. New approaches in the systematics of rickettsiae. New Microbe New Infect. 2018, 23, 93-102. [CrossRef]

5. Portillo, A.; de Sousa, R.; Santibáñez, S.; Duarte, A.; Edouard, S.; Ifonseca, I.P.; Marques, C.; Novakova, M.; Palomar, A.M.; Santos, M. Guidelines for the detection of Rickettsia spp. Vector Borne Zoonotic Dis. 2017, 17, 23-32. [CrossRef]

6. Socolovschi, C.; Mediannikov, O.; Raoult, D.; Parola, P. The relationship between spotted fever group Rickettsiae and ixodid ticks. Vet. Res. 2009, 40,34. [CrossRef]

7. Tomassone, L.; Portillo, A.; Nováková, M.; Sousa, R.; Oteo, J.A. Neglected aspects of tick-borne rickettsioses. Parasit. Vectors 2018, 11, 263. [CrossRef]

8. Iweriebor, B.C.; Mmbaga, E.J.; Adegborioye, A.; Igwaran, A.; Obi, L.C.; Okoh, A.I. Genetic profiling for Anaplasma and Ehrlichia species in ticks collected in the Eastern Cape Province of South Africa. BMC Microbiol. 2017, 17, 45. [CrossRef]

9. Yawa, M.; Nyangiwe, N.; Kadzere, C.T.; Muchenje, V.; Mpendulo, T.C.; Marufu, M.C. In search of the Rhipicephalus (Boophilus) microplus in the western-central regions of the Eastern Cape Province, South Africa. Ticks Tick-Borne Dis. 2019, 10, 564-567. [CrossRef]

10. Parola, P.; Paddock, C.D.; Raoult, D. Tick-borne rickettsioses around the world: Emerging diseases challenging old concepts. Clin. Microbiol. Rev. 2005, 18, 719-756. [CrossRef]

11. Marks, M.; Johnson, V.; Brown, M. Fever in the returned traveler. In Hunter's Tropical Medicine and Emerging Infectious Diseases, 10th ed.; Elsevier: Amsterdam, The Netherlands, 2020; pp. 1077-1086.

12. Walker, A.R.; Bouattour, A.; Camicas, J.L.; Estrada-Pana, A.; Horak, I.G.; Latif, A.A. Ticks of Domestic Animals in Africa; A Guide to Identification of Species; Bioscience Reports: Edinburgh, UK, 2003; ISBN 0-9545173-0-X.

13. Regnery, R.L.; Spruill, C.L.; Plikaytis, B.D. Genotypic identification of rickettsiae and estimation of intraspecies sequence divergence for portions of two rickettsial genes. J. Bacteriol. 1991, 173, 1576-1589. [CrossRef] [PubMed]

14. Eremeeva, M.; Yu, X.; Raoult, D. Differentiation among spotted fever group rickettsiae species by analysis of restriction fragment length polymorphism of PCR-amplified DNA. J. Clin. Microbiol. 1994, 32, 803-810. [CrossRef]

15. Kollars, T.M., Jr.; Kengluecha, A. Spotted fever group Rickettsia in Dermacentor variabilis (Acari: Ixodidae) infesting raccoons (Carnivora:Procyonidae) and opossums (Marsupialia: Didelphimorphidae) in Tennessee. J. Med. Entomol. 2001, 38, 601-602. [CrossRef] [PubMed]

16. Williamson, P.C.; Billingsley, P.M.; Teltow, G.J.; Seals, J.P.; Turnbough, M.A.; Atkinson, S.F. Borrelia, Ehrlichia, and Rickettsia spp. in Ticks Removed from Persons, Texas, USA. Emerg. Infect. Dis. 2010, 16, 3. [CrossRef] 
17. Saitou, N.; Nei, M. The neighbor-joining method: A new method for reconstructing phylogenetic trees. Mol. Biol. Evol. 1987, 4, 406-425.

18. Felsenstein, J. Confidence limits on phylogenies: An approach using the bootstrap. Evolution 1985, 39, 783-791. [CrossRef] [PubMed]

19. Nei, M.; Kumar, S. Molecular Evolution and Phylogenetics; Oxford University Press: New York, NY, USA, 2000.

20. Kumar, S.; Stecher, G.; Tamura, K. MEGA7: Molecular Evolutionary Genetics Analysis version 7.0 for bigger datasets. Mol. Biol. Evol. 2016, 33, 1870-1874. [CrossRef]

21. Robinson, M.T.; Satjanadumrong, J.; Hughes, T.; Stenos, J.; Blacksell, S.D. Diagnosis of spotted fever group Rickettsia infections: The Asian perspective. Epidemiol. Infect. 2019, 147, 1-9. [CrossRef]

22. Fournier, P.; Dumler, J.S.; Greub, G.; Zhang, J.; Wu, Y.; Raoult, D. Gene Sequence-Based Criteria for Identification of New Rickettsia Isolates and Description of Rickettsia heilongjiangensis sp. nov. J. Clin. Microbiol. 2003, 41, 5456-5465. [CrossRef]

23. Ndip, L.M.; Fokam, E.B.; Bouyer, D.H.; Ndip, R.N.; Titanji, V.P.; Walker, D.H. Detection of Rickettsia africae inpatients and ticks along the coastal region of Cameroon. Am. J. Trop. Med. Hyg. 2004, 71, 363-366. [CrossRef]

24. Mediannikov, O.; Diatta, G.; Fenollar, F.; Sokhna, C.; Trape, J.F.; Raoult, D. Tick-borne rickettsioses, neglected emerging diseases in rural Senegal. PLoS Negl. Trop. Dis. 2010, 14. [CrossRef] [PubMed]

25. Consigny, P.H.; Rolain, J.; Mizzi, D.; Raoult, D. African Tick-bite Fever in French Travelers. Emerg. Infect. Dis. 2005, 11, 1804. [CrossRef] [PubMed]

26. Prabhu, M.; Nicholson, W.L.; Roche, A.J.; Kersh, G.J.; Fitzpatrick, K.A.; Oliver, L.D.; Massung, R.F.; Morrissey, A.B.; Bartlett, J.A.; Onyango, J.J.; et al. Q Fever, Spotted Fever Group, and Typhus Group Rickettsioses Among Hospitalized Febrile Patients in Northern Tanzania. Clin. Infect. Dis. 2011, 53, e8-e15. [CrossRef] [PubMed]

27. Jensenius, M.; Fournier, P.E.; Vene, S.; Hoel, T.; Hasle, G.; Henriksen, A.Z.; Hellum, K.B.; Raoult, D.; Myrvang, B.; Norwegian African Tick Bite Fever Study Group. Norwegian African Tick Bite Fever Study Group. African tick bite fever in travelers to rural sub-Equatorial Africa. Clin. Infect. Dis. 2003, 36, 1411-1417. [CrossRef] [PubMed]

28. Nilsson, K.; Wallménius, K.; Rundlöf-Nygren, P.; Strömdah, S.; Påhlso, C. African tick bite fever in returning Swedish travelers. Report of two cases and aspects of diagnostics. Infect. Ecol. Epidemiol. 2017, 7, 1343081. [CrossRef]

29. Socolovschi, C.; Matsumoto, K.; Marie, J.L.; Davoust, B.; Raoult, D.; Parola, P. Identification of rickettsiae, Uganda and Djibouti. Emerg. Infect. Dis. 2007, 13, 1508-1510. [CrossRef]

30. Lorusso, V.; Gruszka, K.A.; Majekodunmi, A.; Igweh, A.; Welburn, S.C.; Picozzi, K. Rickettsia africae in Amblyomma variegatum ticks, Uganda and Nigeria. Emerg. Infect. Dis. 2013, 19, 1705-1707. [CrossRef]

31. Angerami, R.N.; Krawczak, F.S.; Nieri-Bastos, F.A.; Santos, F.; Medorima, C.; Resende, M.R. First report of African tick-bite fever in a South American traveler. SAGE Open Med. Case Rep. 2018, 6. [CrossRef]

32. Harrison, N.; Burgmann, H.; Forstner, C.; Ramharter, M.; Széll, M.; Schötta, A. Molecular diagnosis of African tick bite fever using eschar swabs in a traveler returning from Tanzania. Wien. Klin. Wochenschr. 2016, 128, 602-605. [CrossRef]

33. Nakao, R.; Qiu, Y.; Igarashi, M.; Magona, J.W.; Zhou, L.; Ito, K.; Sugimoto, C. High prevalence of spotted fever group rickettsiae in Amblyomma variegatum from Uganda and their identification using sizes of intergenic spacers. Ticks Tick-Borne Dis. 2013, 4, 506-512. [CrossRef]

34. Waner, T.; Keysary, A.; Eremeeva, M.E.; Din, A.B.; Mumcuoglu, K.Y.; King, R.; Atiya-Nasagi, Y. Rickettsia africae and Candidatus Rickettsia barbariae in Ticks in Israel. Am. Soc. Trop. Med. Hyg. 2014, 90, 920-922. [CrossRef] [PubMed]

35. Yssouf, A.; Socolovschi, C.; Kernif, T.; Temmam, S.; Elagadec, E.; Tortosa, P.; Parola, P. First molecular detection of Rickettsia africae in ticks from the Union of the Comoros. Parasit. Vectors 2014, 7, 444. [CrossRef] [PubMed]

36. Maina, A.N.; Jiang, J.; Omulo, S.A.; Cutler, S.J.; Ade, F.; Ogola, E.; Feikin, D.R.; Njenga, M.K.; Cleaveland, S.; Mpoke, S.; et al. High Prevalence of Rickettsia africae Variants in Amblyomma variegatum Ticks from Domestic Mammals in Rural Western Kenya: Implications for Human Health. Vector-Borne Zoonotic Dis. 2014, 14. [CrossRef] [PubMed] 
37. Ehounoud, C.B.; Yao, K.P.; Dahmani, M.; Achi, Y.L.; Amanzougaghene, N.; N’Douba, A.K.; N'Guessan, J.D.; Raoult, D.; Fenollar, F.; Mediannikov, O. Multiple Pathogens Including Potential New Species in Tick Vectors in Côte d'Ivoire. PLoS Negl. Trop. Dis. 2016. [CrossRef]

38. Paddock, C.D.; Sumner, J.W.; Comer, J.A.; Zaki, S.R.; Goldsmith, C.S.; Goddard, J.; McLellan, S.L.; Tamminga, C.L.; Ohl, C.A. Rickettsia parkeri: A newly recognized cause of spotted fever rickettsiosis in the United States. Clin. Infect. Dis. 2004, 38, 805-811. [CrossRef] [PubMed]

39. Kimita, G.; Mutai, B.; Nyanjom, S.G.; Wamunyokoli, F.; Waitumbi, J. Phylogenetic Variants of Rickettsia africae, and Incidental Identification of "Candidatus Rickettsia Moyalensis" in Kenya. PLoS Negl. Trop. Dis. 2016. [CrossRef]

40. Paddock, C.D.; Finley, R.W.; Wright, C.S.; Robinson, H.N.; Schrodt, B.J.; Lane, C.C.; Ekenna, O.; Blass, M.A.; Tamminga, C.L.; Ohl, C.A.; et al. Rickettsia parkeri rickettsiosis and its clinical distinction from Rocky Mountain spotted fever. Clin. Infect. Dis. 2008, 47, 1188-1196. [CrossRef]

41. Cowdry, E.V. The distribution of rickettsia in the tissues of insects and arachnids. J. Exp. Med. 1993, 37, 431-459. [CrossRef]

42. Parker, R.R.; Kohls, G.M.; Cox, G.W.; Davis, G.E. Observations on an infectious agent from Amblyomma maculatum. Public Health Rep. 1939, 54, 1482-1484. [CrossRef]

43. Chen, L.H.; Wilson, M.E. Tick-Borne Rickettsiosis in Traveler Returning from Honduras. Emerg. Infect. Dis. 2009, 15, 1321-1323. [CrossRef]

44. Romer, Y.; Seijo, A.C.; Crudo, F.; Nicholson, W.L.; Varela-Stokes, A.; Lash, R.R.; Paddock, C.D. Rickettsia parkeri Rickettsiosis, Argentina. Emerg. Infect. Dis. 2011, 17, 1169-1173. [CrossRef] [PubMed]

45. Whitman, T.J.; Richards, A.L.; Paddock, C.D.; Tamminga, C.L.; Sniezek, P.J.; Jiang, J.; Byers, D.K.; Sanders, J.W. Rickettsia parkeri infection after tick bite, Virginia. Emerg. Infect. Dis. 2007, 13, 334-336. [CrossRef] [PubMed]

46. Halajian, A.; Palomar, A.M.; Portillo, A.; Heyne, H.; Romero, L.; Oteo, J.A. Detection of zoonotic agents and a new Rickettsia strain in ticks from donkeys from South Africa: Implications for travel medicine. Travel Med. Infect. Dis. 2018, 26, 43-50. [CrossRef] [PubMed]

47. Imaokaa, K.; Kanekoa, S.; Tabarab, K.; Kusatakea, K.; Morita, E. The First Human Case of Rickettsia tamurae Infection in Japan. Case Rep. Dermatol. 2011, 3, 68-73. [CrossRef] [PubMed]

48. Thu, M.J.; Qiu, Y.; Matsuno, K.; Kajihara, M.; Mori-Kajihara, A.; Omori, R.; Monma, N.; Chiba, K.; Seto, J.; Gokuden, M.; et al. Diversity of spotted fever group rickettsiae and their association with host ticks in Japan. Sci. Rep. 2019, 9, 1500. [CrossRef]

49. Motoi, Y.; Asano, M.; Inokuma, H.; Ando, S.; Kawabata, H.; Takano, A.; Suzuki, M. Detection of Rickettsia tamurae DNA in ticks and wild boar (Sus scrofa leucomystax) skins in Shimane Prefecture, Japan. J. Vet. Med. Sci. 2013, 75, 263-267. [CrossRef]

50. Gaowa, N.O.; Aochi, M.; Wuritu, W.D.; Yoshikawa, Y.; Kawamori, F.; Honda, T.; Fujita, H.; Takada, N.; Oikawa, Y.; Kawabata, H.; et al. Rickettsiae in Ticks, Japan, 2007-2011. Emerg. Infect. Dis. 2013, 19, 338-340. [CrossRef]

51. Blanco, C.M.; Teixeira, B.R.; da Silva, A.G.; de Oliveira, R.C.; Strecht, L.; Ogrzewalska, M.; de Lemos, E.R.S. Microorganisms in ticks (Acari: Ixodidae) collected on marsupials and rodents from Santa Catarina, Paraná and Mato Grosso do Sul states, Brazil. Ticks Tick-Borne Dis. 2017, 8, 90-98. [CrossRef]

(C) 2020 by the authors. Licensee MDPI, Basel, Switzerland. This article is an open access article distributed under the terms and conditions of the Creative Commons Attribution (CC BY) license (http://creativecommons.org/licenses/by/4.0/). 